Jurnal Keperawatan, Volume 9, No. 1, Februari 2021, (Hal. 48-55)

\title{
HUBUNGAN TINGKAT STRESS DENGAN KUALITAS TIDUR PADA PASIEN DIABETES MELITUS TIPE 2 DI RUMAH SAKIT GMIM PANCARAN KASIH MANADO
}

\author{
Cindy Sweetenia Sumiok ${ }^{1,}$ Agnes Madianung, ${ }^{2,}$ Mario Esau Katuuk ${ }^{3}$ \\ ${ }^{1}$ Mahasiswa Program Studi Ilmu Keperawatan Fakultas Kedokteran Universitas Sam \\ Ratulangi, Manado \\ ${ }^{2}$ RSUP Prof DR R.D Kandou Manado \\ ${ }^{1}$ Program Studi Ilmu Keperawatan Fakultas Kedokteran Universitas Sam Ratulangi Manado \\ Email : sumiokcindy@gmail.com
}

\begin{abstract}
Patients with type 2 diabetes mellitus usually experience severe stress so that patients have poor sleep quality, sleep quality is closely related to emotional stress which can have an impact on sleep quality. The purpose of this study was to determine the relationship between stress levels and sleep quality in patients with type 2 diabetes mellitus. Research Methods Using aapproach cross sectional. Respondents consisted of 75 respondents with a sampling technique by means of purpose sampling. Measurement of stress levels was carried out using the DDAS (Depression Anxiety Stress Scale) questionnaire. And the measurement of sleep quality was done using the PSQI (Pittsburgh Sleep Quality Index) questionnaire. Test results show that there is a relationship between stress levels and sleep quality inpatients type 2 diabetes mellitus at Pancaran Kasih Hospital Manado. Where the p-value $=0.011$ is smaller than $\alpha=(0.05)$, the conclusion of this study shows that stress levels affect the quality of sleep in patients with type 2 diabetes mellitus. Suggestion The results of this study are expected to be used as information and input for Pancaran Hospital. The love of GMIM Manado especially for nurses to be a reference in handling stress levels in type 2 Diabetes Mellitus patients.
\end{abstract}

Keywords : Stress Level, Sleep Quality, Type 2 Diabetes Mellitus Patients

Abstrak Penderita diabetes mellitus tipe 2 biasanya mengalami stress berat sehingga penderita memiliki kualitas tidur yang buruk, kualitas tidur sangat berhubungan erat dengan stress emosional yang bisa berdampak pada kualitas tidur. Tujuan Penelitian ini di lakukan untuk mengetahui hubungan antara tingkat stress dengan kualitas tidur pada pasien diabetes mellitus tipe 2. Metode Penelitian Menggunakan pendekatan cross sectional. Responden terdiri dari 75 responden dengan teknik pengambilan sampel dengan cara purpose sampling. Pengukuran Tingkat stress dilakukan dengan menggunakan kuisioner DDAS (Depression Anxiety Stress Scale). Dan pengukuran kualitas tidur dilakukan dengan menggunakan kuisioner PSQI (Pittsburgh Sleep Quality Index). Hasil Uji Menunjukan adanya hubungan antara tingkat stress dengan kualitas tidur pada pasien diabetes mellitus tipe 2 di rumah sakit Pancaran Kasih Manado. Dimana $p$-value $=0,011$ lebih kecil dari $\alpha=(0,05)$, Kesimpulan hasil penelitian ini menunjukkan bahwa faktor tingkat stress mempengaruhi kualitas tidur pada pasien diabetes mellitus tipe 2. Saran Hasil penelitian ini Diharapkan dapat dijadikan informasi dan masukkan bagi Rumah Sakit Pancaran Kasih GMIM Manado terutama bagi perawat untuk bisa menjadi acuan dalam penanganan tingkat stress pada pasien Diabetes Melitus tipe 2

Kata Kunci : Tingkat Stres, Kualitas Tidur, Pasien Diabetes mellitus tipe 2 


\section{PENDAHULUAN}

Diabetes melitus merupakan penyakit gangguan metabolisme kronis yang ditandai dengan peningkatan glukosa darah (Hiperglikemi), disebabkan karena ketidak- seimbangan antara suplai dan kebutuhan untuk memfasilitasi masuknya glukosa dalam sel agar dapat di gunakan untuk metabolisme dan pertumbuhan sel. Berkurang atau tidak adanya insulin menjadikan glukosa tertahan di dalam darah dan menimbulkan peningkatan gula darah, sementara sel menjadi kekurangan glukosa yang sangat di butuhkan dalam kelangsungan dan fungsi sel (Izzati \&Nirmala, 2015).Diabetes melitus terbagi menjadi dua tipe yaitu tipe 1 dan tipe 2 . Individu yang menderita Diabetes melitus tipe 1 memerlukan suplai insulin dari luar (eksogen insulin), seperti injeksi untuk mempertahankan hidup. Tanpa insulin pasien akan mengalami diabetik ketoasidosis, kondisi yang mengancam kehidupan yang dihasilkan dari asidosis metabolik.

Ditemukan bahwa seluruh penderita diabetes mellitus tipe 2 yang mengalami stres tingkat tinggi memiliki kualitas tidur buruk. Stres dan tidur mempunyai hubungan yang sangat erat, stres emosional menyebabkan seseorang menjadi tegang dan sering kali mengarah frustasi apabila tidur.Stres merusak keseimbangan alamiah dalam diri manusia,mengalami keadaan stres merusak kesehatan tubuh dan berdampak pada beragam gangguan fungsi tubuh salah satunya dampaknya adalah kesulitan tidur.Sehingga stress yang berlanjut dapat menyebakan kebiasaan tidur buruk (Nugroho \& Purwanti, 2010).

Fenomena yang peneliti jumpai sewaktu melakukan praktik keperawatan di Rumah sakit Pancaran Kasih GMIM Manado,yakni bahwa pasien yang mengalami Diabetes melitus tipe 2 saat di wawancara beberapa dari mereka menjelaskan bahwa mereka sulit untuk beristirahat karena stress penyakit yang di derita,sehingga kadar gula darah meningkat dan merasa sesuatu yang membuat mereka mudah untuk cepat marah, sulit untuk beristirahat,dan sesekali terbangun di malam hari untuk berkemih.Data terbaru mengenai jumlah kunjungan pasien dengan Diabetes melitus dan hasil pengambilan data awal di bagian rekam medik di Rumah Sakit Umum GMIM Pancaran Kasih Manado,diketahui dari bulan Januari-Maret 2019 ada sebanyak 302 kunjungan pasien baru di rawat jalan. Juga hasil dari kunjungan sehari di Poliklinik Endokrin RSU GMIM Pancaran Kasih Manado pada tanggal 25 Maret 2019 di peroleh data dari hasil observasi di 20 pasien yang datang berkunjung dengan 15 orang mengalami stress dan kualitas tidur terganggu.Hasil wawancara dengan 15 orang mengalami stress dan kualitas tidur terganggu karna sering mudah marah ,mudah tersinggung, merasa sulit beristirahat,sesekali terbangun di malam hari,atau pagi-pagi sekali selalu bangun untuk ke kamar mandi.Berdasarkan data yang ada dan fenomena yang di temui maka penulis tertarik untuk melakukan penelitian tentang "Hubungan Tingkat Stres Dengan Kualitas Tidur Pada Pasien Diabetes Mellitus Tipe 2 Di Poliklinik Endokrin RSU GMIM Pancaran Kasih Manado “.

\section{METODE}

Jenis penelitian yang digunakan dalam penelitian kuantitatif yang bersifat analitik dengan desaini penelitian Cross Sectional, Penelitian ini dilaksanakan di Rumah Sakit Pancaran Kasih GMIM Manado dalam waktu 3 bulan yaitu bulan Maret - juli 2019. Populasi pada penelitian ini adalah pasien Rawat Jalan di Rumah Sakit Pancaran Kasih GMIM Manado. Penetuan jumlah sampel pada penelitian ini yaitu menggunakan purposive sampling, dengan jumlah sampel 75 yang telah mematuhi kriteria inkluisi yaitu : bersedia menjadi responden, .pasien diabetes melitus 2 di Poliklinik Endokrin Rumah sakit GMIM Pancaran Kasih Manado, .Pasien Diabetes melitus tipe 2 yang dalam keadaan sadar, 
hadir saat pengambilan data dan mengisi kuisioner dengan lengkap. Dan untuk kriteria eksklusi yaitu, tidak bersedia menjadi responden ,pasien yang mengonsumsi obat tidur atau penenang. Kuisioner tingkat stress terdiri dari 14 pertanyaan dan kuisioner ini sudah pernah diteliti oleh Derek,(2017) di mana diberikan : $0=$ Tidak pernah , $1=$ Kadangkadang , $2=$ Sering , $3=$ Sering sekali.Dan kuisioner kualitas tidur terdiri dari 9 pertanyaan dengan masing-masing pertanyaan di beri skor 0-3. Penelitian ini menggunakan data primer yaitu data yang diperoleh langsung dari responden dan data sekunder yaitu diperoleh langsung dari rekapitulsi jumlah pasien diabetes mellitus tipe 2 di Rumah Sakit Pancaran Kasih GMIM Manado.

Pengolahan data pada penelitian ini diperoleh dari hasil secara manual dengan menggelompokan hasil dari lembar kuisioner yang dibagikan selanjutnya dilakukan analisis menggunakan uji statistik. Setelah diolah menggunakan sistem komputerisasi, tahap-tahap tersebut yaitu editing,coding,transferring,tabulating, dan analisa univariate yang dilakukan untuk menganalisa variabel tingkat stress dan kualitas tidur. Analisa bivariate yang digunakan adalah hasil tabulasi silang. Untuk menguji hipotesa dilakukan analisa kemaknaan 95\% ( $\rho$-Value< 0,05$)$. Setelah di uji hasil memenuhi syarat yaitu $\mathrm{p}=0,003$ dan ditarik suatu kesimpulan dimana nilai ( $\rho$-Value $<0,05)$. Maka sesuai dengan Hipotesis awal bahwa ada hubungan antara variabel dependen dan variabel independen. Selain itu menjaga keamanan responden digunakan standar operasional yaitu lembar persetujuan (informed concent) meminta persetujuan kepada responden apakah bersedia atau tidak menjadi responden, yang kedua tampa nama (anonymity) dengan tidak mencantumkan nama lengkap namun hanya dengan inisial, yang ketiga kerahasiaan (confidentiality)tidak menampilkan informasi mengenai identitas hingga jawaban dari tiap responden yang di teliti. Juga telah mendapatkan izin dari pihak rumah sakit umum Pancaran Kasih GMIM Manado dengan nomor surat (24/04/RSPK/VIII/2019).

\section{HASIL}

\section{Karakteristik Responden}

Tabel 5.2.1 Distribusi sampel berdasarkan umur di Rumah Sakit GMIM Pancaran Kasih Manado

\begin{tabular}{ccc}
\hline Umur & Frekuensi & \% \\
$\mathbf{3 7 - 4 6}$ & 4 & 5,3 \\
$\mathbf{4 7 - 5 6}$ & 27 & 36,0 \\
$\mathbf{5 7 - 7 4}$ & 44 & 58,7 \\
Total & 75 & 100,0 \\
\hline
\end{tabular}

\section{Sumber : Data Primer 2019}

Hasil penelitian berdasrkat tabel di atas menunjukan bahwa sebagian besar berada pada rentang umur 57-74 tahun yaitu sebanyak 44(58,7\%) . rentang umur 47-56 tahun yaitu sebanyak 27(36,0\%) dan sisanya berada pada rentang umur 37-46 tahun sebanyak 4(5,3\%). 
Jurnal Keperawatan, Volume 9, No. 1, Februari 2021, (Hal. 48-55)

Tabel 5.2.2 Distribusi sampel berdasarkan jenis kelamin Rumah Sakit GMIM Pancaran Kasih Manad

\begin{tabular}{ccc}
\hline Jenis Kelamin & Frekuensi & \% \\
Laki-laki & 30 & 40,0 \\
Perempuan & 45 & 60,0 \\
Total & 75 & 100,0 \\
\hline
\end{tabular}

Sumber : Data Primer 2019

Hasil penelitian berdasarkat dia atas menunjukan bahwa sebagian besar sampel berjenis kelamin perempuan yaitu sebanyak $45(60,0 \%)$, dan sisanya berjenis kelamin laki-laki yaitu sebanyak 30(40\%).

\section{Analisa Univariat}

Tabel distibusi responden motivasi dan kinerja

Tabel 5.3.1 Distribusi responden berdasarkan Tingkat Stress Rumah Sakit GMIM Pancaran Kasih Manado

\begin{tabular}{ccc}
\hline Tingkat Stress & Frekuensi & $\boldsymbol{\%}$ \\
Sedang & 10 & 13,3 \\
Berat & 65 & 86,7 \\
Total & 75 & 100,0 \\
\hline
\end{tabular}

Sumber : Data Primer 2019

Hasil penelitian berdasarkan tabel di atas 65(86,7\%) sisanya berada pada kategori menunjukan bahwa besar sampel berada pada kategori berat yaitu sebanyak sedang yaitu sebanyak 10(13,3\%)

Tabel 5.3.2 Distribusi responden berdasarkan Kualitas Tidur Rumah Sakit GMIM Pancaran Kasih Manado

\begin{tabular}{ccc}
\hline Kualitas Tidur & Frekuensi & $\%$ \\
Baik & 29 & 38,7 \\
Buruk & 46 & 61,3 \\
Total & 75 & 100,0 \\
\hline
\end{tabular}

Sumber : Data Primer 2019

Hasil penelitian berdasarkan tabel diatas menunjukan bahwa besar sampel berada sisanya berada pada kategori baik yaitu pada kategori buruk sebanyak 46(61,3\%), sebanyak 29(38,7\%). 


\section{Analisis Bivariat}

Tabel 5.4 hubungan tingkat strees dengan kualitas tidur

\begin{tabular}{lrrrr}
\hline Tingkat Strees Kualitas tidur & Baik & Buruk & Total & P value \\
Sedang & 8 & 2 & 10 & \\
Berat & 21 & 44 & 65 & 0,011 \\
Total & 29 & 46 & 75 & \\
\hline
\end{tabular}

Hasil penelitian dari 75 responden yang terjangkau selama penelitian menunjukan hasil paling banyak responden yang tingkat streesnya, berat kualitas tidurnya buruk. Dan sisanya responden yang tingkat streesnya sedang kualitas tidurnya baik. Hasil uji statistik dengan menggunakan uji chi Square yang dilanjutkan dengan uji Fisher Exact dengan tingkat kepercayaan $95 \%$ ( $\alpha$ 0,05), menunjukan adanya hubungan yang signifikan antara hubungan tingkat strees dengan kualitas tidur pada pasien diabetes mellitus tipe 2 di Rumah Sakit Pancaran Kasih Gmim Manado. Di mana $p$ value $=0,011$ lebih kecil dari $\alpha=0,05$.

\section{PEMBAHASAN}

Hasil penelitian dari 75 responden yang terjangkau selama penelitian menunjukan hasil paling banyak responden Tingkat stressnya, Berat Kualitas Tidurnya Buruk. Dan sisanya responden yang Tingkat Stressnya sedang, Kualitas Tidurnya Baik. Hasil uji statistic dengan menggunakan uji Chi Square yang di lanjutkan dengan uji Fisher Exact dengan tingkat kepercayaan $95 \%(\alpha 0,05)$,menunjukan adanya hubungan yang signifikan antara hubungan tingkat stress dengan kualitas tidur pada pasien diabetes mellitus tipe 2 di Rumah Sakit Pancaran Kasih Manado. Dimanap-value $=$ 0,011 lebih kecil dari $\alpha=0,05$.

Berdasarkan hasil dari kunjungan sehari di Poliklinik Endokrin RSU GMIM Pancaran Kasih Manado pada tanggal 25 Maret 2019 di peroleh data dari hasil observasi di 20 pasien yang datang berkunjung dengan 15 orang mengalami stress dan kualitas tidur terganggu.Hasil wawancara dengan 15 orang mengalami stress dan kualitas tidur terganggu karna sering mudah marah ,mudah tersinggung, merasa sulit beristirahat,sesekali terbangun di malam hari,atau pagi-pagi sekali selalu bangun untuk ke kamar mandi.

Diabetes melitus dapat disebabkan oleh banyak faktor, diantaranya adalah faktor keturunan/genetik, obesitas, perubahan gaya hidup, polamakan yang salah, obato batan yang mempengaruhi kadar glukosa darah, kurangnya aktivitas fisik, proses menua, kehamilan, perokok dan Stress, (Muflihatin, 2015).

Berdasarkan hasil penelitian pada tabel distribusi responden menunjukan bahwa sebagian besar responden penderita Diabetes Melitus tipe 2 berjenis kelamin perempuan yaitu sebanyak $45(60 \%)$.

Tandra (2013) menyatakan bahwa perempuan memiliki resiko lebih besar untuk menderita Diabetes Melitus tipe 2 dibandingkan laki - laki, berhungan dengan kehamilan dimana kehamilan merupakan faktor resiko untuk terjadinya penyakit Diabetes Melitus.Pada ibu hamil hormon ikut berperan karena tubuh perempuan menghasilakn beberapa hormone dalam jumlah banyak saat hamil. Salah satunya adalah hormon yang mengganggu bekerjanya insulin. Ada hormon yang erat kaitannya dengan diabetes, yaitu hormon pertumbuhan $(\mathrm{GH})$, human placenta 
lactogen $(\mathrm{Hpl})$, dan kortisol insulin. Jika terjadi gangguan pada hormon tersebu dapat menyebabkan intoleransi gula darah dan menyebabkan diabetes. Penelitian jenis kelamin dengan kejadian Diabetes Melitus tipe 2, prevalensi kejadian Diabetes Melitus tipe 2 pada wanita lebih tinggi daripada laki - laki , wanita lebih beresiko mengidap Diabetes Melitus tipe 2 karena secara fisik wanita memiliki peluang peningkatan Indeks masa tubuh yang lebih besar, rata rata kematian pasien penderita Diabetes Melitus 72,29 \pm 8,87 tahun lebih banyak wanita dibandingkan dengan laki - laki 71,35 \pm 9,06 tahun (Loacara, 2007).

Ditemukan bahwa seluruh penderita diabetes mellitus tipe 2 yang mengalami stres tingkat tinggi memiliki kualitas tidur buruk., Stres dan tidur mempunyai hubungan yang sangat erat,stres emosional menyebabkan seseorang menjadi tegang dan sering kali mengarah frustasi apabila tidur.

Kualitas tidur yang buruk bagi pasien Diabetes melitus adalah sering berkemih pada malam hari, makan berlebihan serta peningkatan suhu tubuh dapat mengganggu pola tidur dimalam hari, sehingga menyebabkan kurangnya kualitas tidur. Beberapa gangguan respon imun, metabolisme endokrin, dan fungsi kardiovaskular (Caple \& Grose, 2011). penelitian Harista dan Lisiswati (2015) bahwa resiko Stress pada penderita diabetes mellitus di sebabkan oleh stressor psikososial kronik karna mengidap penyakit kronik. Sebaliknya, stress dapat menjadi faktor resiko diabetes mellitus. Secara teori, hal ini diakibatkan dari proses peningkatan sekresi dan aksi hormone kontraregulasi, perubahan fungsi transport glukosa dan peningkatan aktivasi inflamasi

\section{SIMPULAN}

Berdasarkan hasil penelitian yang dilakukan peneliti di Rumah Sakit Pancaran GMIM Manado di dapatkan kesimpulan yaitu, ada hubungan antara tingkat stress dengan kualitas tidur pasien diabetes mellitus tipe 2 di Rumah Sakit Pancaran Kasih GMIM Manado. Hasil penelitian ini Diharapkan dapat dijadikan informasi dan masukkan bagi Rumah Sakit Pancaran Kasih GMIM Manado terutama bagi perawat untuk bisa menjadi acuan dalam penanganan tingkat stress pada pasien Diabetes Melitus tipe 2 Rumah Sakit Pancaran Kasih GMIM Manado.

\section{DAFTAR PUSTAKA}

Amin Huda Nurarif \& Hardhi Kusuma (2015). Asuhan Keperawatan Berdasarkan Diagnosa Medis Nanda NIC-NOC . Yogyakarta : Medi action

Arifin Z. Analisis Hubungan Kualitas Tidur Dengan Kadar Glukosa Darah Pasien Diabetes Mellitus Tipe 2 di RSU Nusa Tenggara Barat. Universitas Indonesia. Depok. 2011

Bilous, R , \& Richard, D.(2015 ). Buku Pegangan Diabetes (Edisi 4 ).

Kelana, Kusuma .(2011). Metodologi

Penelitian Keperawatan .Jakarta

Timur :Trans Info Media

Caple, Grose. (2011). Sleep and hospitalization : evidance-based care sheet. Cinahl information system. 69 (4): 1-4.

Hutapea, freddly (2007). Gaya hidup, Dalam http://depkes .go.id.

IDS,(2008),Hubungan Erat Metabolik Sindroma dan Depresi http://www.kalbe.co.id.

International Diabetes Federation. (2015). IDF Diabetes Atlas Seventh Edition 2015. Dunia : IDF

https://azskincancerinstitute.org/sites/defau lt/files/psqi_sleep_questionnaire_1_pg.pdf Buysse, D.J., Reynolds III, C.F., Monk, T.H., Berman, S.R., \& Kupfer, D.J. (1989). The Pittsburgh Sleep 
Quality Index: A new instrument for psychiatric practice and research. Journal of Psychiatric Research, 28(2), 193-213.Reprinted with permission from copyright holder for educational purposes per the University of Pittsburgh,Sleep Medicine Institute, Pittsburgh Sleep

http://www.sleep.pitt.edu/content.asp?id=1 484\&subid=2316.

Quality Index (PSQI) Website

https://consultgeri.org/try-this/generalassessment/issue-6.1.pdf

Buysse, D.J., Reynolds III, C.F., Monk, T.H., Berman, S.R., \& Kupfer, D.J. (1989). The Pittsburgh Sleep Quality Index: A new instrument for psychiatric practice and research. Journal of Psychiatric Research, 28(2), 193-213.Reprinted with permission from copyright holder for educational purposes per the University of Pittsburgh, Sleep Medicine Institute, Pittsburgh Sleep

Inry N.Tentero (2016) Hubungan Diabetes Melitus dengan kualitas tidur Jurnal e-Biomedik (eBm), Volume 4, Nomor 2, Juli-Desember 2016

https://media.neliti.com/media/publi cations/64654-ID-hubungandiabetes-melitus-dengan-kualitas.pdf

Izzati, W. \& Nirmala. (2015). Hubungan Tingkat Stres Dengan Peningkatan Kadar Gula Darah Pada Pasien Diabetes Melitus Di Wilayah Kerja Puskesmas Perkotaan Rasimah Ahmad, Bukit Tinggi. Jurnal Program Studi D III Keperawatan STIKes Yarsi Sumbar Bukittinggi.

Jessy Kurnia (2017) Hubungan Kualitas tidur denga kadar glukosa darah puasa pada pasien Diabete Melitus tipe II di RSU GMIM Pancaran kasih Manado https://ejournal.unsrat.ac.id/index.ph $\mathrm{p} / \mathrm{jkp} /$ article/view/14730/14298

Labetubun NS. (2014) Hubungan Antara Kualitas Tidur Dengan Kadar Glukosa Darah Pada Penderita Diabetes Mellitus Tipe 2 di RSUD Dr. Moewardi. Fakultas kedokteran Universitas Muhammadiyah Surakarta.

Meivy I. Derek (2017) Hubungan tingkat stress dengan kadar glukosa darah pada pasien Diabetes Melitus tipe II di RSU GMIM Pancaran Kasih Manado https://ejournal.unsrat.ac.id/index.ph $\mathrm{p} / \mathrm{jkp} /$ issue/archive

Muhammad Dien Iqbal, (2017) Hubungan aktivitas fisik denga kualitas tidur mahasiswa perantau yogyakrta.Prodi pendidikan jasmani dan kesehatan dan rekreasi fakultas ilmu keolahragaan universitas negri Yogyakarta

Notoatmodjo, S (2012) Metodologi Penelitian Kesehatan .Jakarta : Rineka Cipta

Muflihatin, K.S. (2015). Hubungan Tingkat Stres Dengan Kadar Glukosa Darah Pasien Diabetes Melitus tipe 2 Di RSUD Abdul Wahab Syahranie Samarinda. Jurnal STIKES Muhammadiyah Samarinda.

Nasriati, R. (2013). Stres dan Perilaku Pasien DM dalam Mengontrol Kadar Gula Darah. Jurnal Fakultas Ilmu Kesehatan Universitas Muhammadiyah Ponorogo

Nugroho, A.S. \& Purwanti, S.O. (2010). Hubungan Antara Tingkat Stres Dengan Kadar Gula Darah Pada Pasien Diabetes Melitus Di Wilayah Kerja Puskesmas Sukoharjo I Kabupaten Sukoharjo 
Perkumpulan Endokrinologi Indonesia (PERKENI,) (2011). Konsensus pengolaan Diabetescdan pencegahan Diabetes Melitus Tipe 2 di Indonesia .Jakarta :PB.PERKENI

Potter \& Perry (2010). Buku Ajar fundamental Keperawatan : konsep, Proses, dan praktik. Edisi 4. Jakarta : EGC.

PSIK Universitas sam Ratulangi. (2013). Panduan Penulisan Tugas Akhir Proposal dan Skripsi. Manado

RISKESDAS. Badan Penelitian Pengembangan Kesehatan Kementerian Kesehatan RI 2013. Riset Kesehatan Daerah. Jakarta: Riskesdas: 2013

Rasmun. (2009) . Stres, Koping dan Adaptasi . Jakarta : Sagung seto

Setiadi. (2013).Konsep dan praktik penulisan Riset Keperawatan (ed.2 ). Yogyakarta :Graha Ilmu

Taub, M.L., Redeker, S.N. (2008). Sleep Disorder, Glukose Regulation And Type 2 Diabetes.Biology Research Nursing. Volume 9.

WHO. (2016 ).Diabetes: Fakta Dan Angka . World Health Organization Sagala VP. Budiatri F. Kualitas tidur dan faktor-faktor gangguan tidur [journal]. [Medan]: UniversitasSumatera Utara; 2013

Yuliana Elin, Andrajat Retnosari, 2009. ISO Farmakoterapi. Jakarta : ISFI

Misnadiarly.(2006). Klasifikasi diabetes mellitus, Bogor Agrikultural University https://repository.ipb.ac.id/bitstream/ handle/123456789/27224/B10efi_B AB\%20II.\%20Tinjauan\%20Pustaka. pdf; sequence $=8$
Hasdiana. (2012).Mengenal Diabetes Mellitus Pada Orang Dewasa dan Anakanak Dengan solusi helbal, Yogyakarta : Nuha medika 